\title{
La exigibilidad de los Convenios de Accionistas frente a la sociedad y el principio de relatividad contractual
}

Joyce Moore MurPhy

Abogada por la Universidad de Lima. Miembro Asociado de ADV Editores - Revista ADVOCATUS.

SUMARI0:

I. Introducción.

II. Marco conceptual.

1. Los alcances de la Autonomía Privada.

2. Los Convenios de Accionistas.

III. Planteamiento del problema.

IV. Análisis del artículo 8 de la Ley General de Sociedades.

1. ¿Qué implica que el Convenio le sea exigible a la sociedad?

2. Sobre las partes en el Convenio de Accionistas.

3. La calidad de accionista como condición de eficacia de un Convenio de Accionistas.

V. Efectos de la anotación del Convenio en la matrícula de acciones.

VI. Conclusiones. 


\section{RESUMEN:}

El siguiente artículo expondrá motivos sobre por qué la Ley General de Sociedades requiere ser mejorada, a fin de precisar en qué supuestos un convenio de accionistas puede imponerle obligaciones a la sociedad y en qué casos puede serle únicamente oponible. Asimismo, propone que la aplicación de dicha norma debe darse a través de una interpretación sistemática con el Código Civil.

Palabras clave: Ley General de Sociedades, Convenios de Accionistas, Exigibilidad.

\section{ABSTRACT:}

The following article will address the topic of why should the Peruvian General Corporations Law be modified, in order to specify in which cases a shareholders agreement can impose obligations on the company and in which cases it can only be opposable. Moreover, the author will proposes that the application of said law should be done through a systematic interpretation with the Civil Code.

Keywords: General Corporations Law, Shareholder's Agreements, Enforceability.

\section{INTRODUCCIÓN}

En la práctica societaria, nadie cuestiona que, como precepto general, un convenio de accionistas debidamente comunicado a la sociedad le sea exigible a esta última, conforme al propio verso de la ley. Sin embargo, son menos las veces en las que la administración de la sociedad hace un análisis sobre qué significa realmente que dicho convenio le sea exigible.

En las líneas siguientes, explicamos por qué consideramos que la Ley General de Sociedades requiere ser mejorada, a fin de precisar en qué supuestos un convenio de accionistas puede imponerle obligaciones — dar, hacer o no hacer-a la sociedad y en qué casos puede serle únicamente oponible, imponiéndole un deber de tolerar su existencia y de no impedir su ejecución.

Hasta que dicha modificación no ocurra, consideramos que el artículo 8 de la Ley General de Sociedades no puede aplicarse de manera literal, sino que su aplicación debe ser el resultado de la interpretación sistemática del mismo y del artículo 1363 del Código Civil.

\section{MARCO CONCEPTUAL}

\section{Los alcances de la autonomía privada.}

De la autonomía privada', se desprenden dos manifestaciones de la libertad: la libertad de contratar y la libertad contractual. Esto es (i) la libertad de decidir si se contrata o no y con quién; y (ii) la posibilidad de determinar libremente el contenido del contrato, siempre que no se trasgreda el orden público, las buenas costumbres ni las normas imperativas.

En relación a ello, de acuerdo a Juan Espinoza Espinoza, sobre la base de lo señalado por Luis Diez-Picazo y Antonio Gullón:

"(...) el gobierno individual de las relaciones jurídicas en que el individuo toma parte, a través de la autonomía privada, se desarrolla en un doble sentido:

a) Es un poder de constitución de relaciones jurídicas;

b) Es un poder de reglamentación del contenido de las relaciones jurídicas"2.

1. Entendida como "el poder reconocido a los sujetos privados (particulares) para la ordenación de las relaciones $e$ intereses propios." PALACIOS MARTÍNEZ, Eric. Autonomía privada, principio de legalidad y derecho civil. En: Derecho PUCP. Revista de la Facultad de Derecho. №60. Lima: 2007, p. 101.

2. ESPINOZA ESPINOZA, Juan. "Los principios contenidos en el Título Preliminar del CC peruano de 1984". Lima: Grijley, 2011 , p. 315. 
De lo anterior se desprende, además, lo expresado en el artículo 1352 del Código Civil, según el cual "los contratos se perfeccionan por el consentimiento de las partes". Es así que, a fin de obligarse frente a terceros, las partes deben brindar su consentimiento haciendo uso de su libertad de contratar y no existirá contrato hasta que las partes no hayan brindado dicho consentimiento respecto de todas sus estipulaciones - artículo 1359 del Código Civil-.

En la misma línea, el principio de relatividad contractual dicta que los contratos son obligatorios únicamente respecto de las partes que los hayan celebrado - i.e. hayan brindado su consentimiento-. En los términos del artículo 1363 del Código Civil:

"Artículo 1363.- Los contratos sólo producen efectos entre las partes que los otorgan y sus herederos, salvo en cuanto a éstos si se trata de derechos y obligaciones no trasmisibles" (el subrayado es nuestro).

Al respecto, Óscar Sumar y Luis Miguel Velarde precisan que:

“(...) según este principio, recogido en el artículo 1363 del Código Civil, los contratos solo surten efectos entre las partes que lo celebran y sus sucesores o cesionarios, de ser el caso. Este principio responde al sentido común y puede también considerarse como una derivación de la autonomía privada. En efecto, es lógico pensar que, si alguien no interviene en un contrato, el mismo no debería generar efectos en su esfera jurídica - crear derechos, obligaciones u otras situaciones jurídicas-; de lo contrario, su esfera jurídica se vería alterada sin su consentimiento, lo que resultaría inadmisible $e^{\prime \prime 3}$.

Se observa entonces que la libertad de contratar tiene como límite, además del orden público, las buenas costumbres y las normas imperativas, la esfera jurídica de las partes que brindaron su consentimiento a la celebración del contrato y que, por tanto, determinaron el contenido del mismo.

Hasta aquí, es sencillo concluir, como principio, que un contrato celebrado entre Primera Compañía S.A. y Segunda Compañía S.A. no puede imponer obligaciones a Tercera Compañía S.A.

\section{Los convenios de accionistas.}

Los convenios entre accionistas, o entre estos y terceros, en tanto que son acuerdos de voluntades para crear, modificar o extinguir relaciones jurídicas patrimoniales, se rigen por el derecho contractual, incluyendo las normas contenidas en la sección primera - Contratos en General- del Libro VII —Fuentes de las Obligaciones- del Código Civil.

Como contratos que son, pueden tener un contenido diverso, pero su función suele ser regular asuntos relativos al gobierno de la sociedad de la cual las partes son accionistas y a la propiedad de sus acciones.

En ese orden de ideas, Enrique Elías Laroza señaló que:

"(...) los convenios entre socios tienen una variedad y multiplicidad imposible de resumir. Por citar solamente algunos ejemplos, puede tratarse de pactos de limitación del derecho de transferir acciones, de formas obligatorias en que una mayoría se compromete a administrar y dirigir la sociedad, de sindicatos de voto o de bloqueo, de formas en que se realizarán futuros aumentos de capital, de las condiciones de los futuros aportes, del ingreso de nuevos socios, de la forma en que un grupo de socios no sufra la dilución de un porcentaje en el capital por futuros aportes, de derechos especiales que se otorgarán a nuevos socios, de prohibiciones temporales a la venta de acciones o a la cesión de los

3. SUMAR ALBÚJAR, Óscar y VELARDE SAFFER, Luis Miguel. “Contratos: Teoría y práctica. Aportes del derecho comparado". Lima: Universidad del Pacífico, 2015, p. 46. 
derechos de voto, de formas preestablecidas de amortización de acciones, de creación de acciones preferenciales, de cláusulas obligatorias de consentimiento, de reglas especiales de competencia con la sociedady otros muchos"'.

Las partes en un convenio de accionistas pueden ser todos los accionistas de una sociedad, solo algunos de ellos o accionistas y terceros ajenos a la sociedad, así como todas las anteriores con o sin la participación de la sociedad.

Asimismo, pueden existir convenios (i) celebrados, comunicados a la sociedad y anotados en la matrícula de acciones; (ii) celebrados y comunicados a la sociedad, pero no anotados en la matrícula de acciones; y (iii) celebrados, pero no comunicados a la sociedad ni anotados en la matrícula de acciones.

Si bien la Ley General de Sociedades no prevé reglas diferentes para cada una de las variantes descritas - excepto al señalar que los convenios comunicados a la sociedad le son exigibles-, conforme describiremos más adelante, las partes en el convenio y la comunicación del mismo a la sociedad son relevantes para el análisis respecto a su exigibilidad frente a la sociedad.

\section{PLANTEAMIENTO DEL PROBLEMA}

La norma sobre la cual se centra este análisis es el artículo 8 de la Ley General de Sociedades, según el cual:

"Son válidos ante la sociedad y le son exigibles en todo cuanto le sea concerniente, los convenios entre socios o entre estos y terceros, a partir del momento en que le sean debidamente comunicados (...)".

Leemos en este artículo que, contrariamente a lo sostenido en la sección 2.1 de nuestro Marco Conceptual, son válidos y le son exigibles a Ter- cera Compañía S.A., los convenios entre Primera Compañía S.A. y Segunda Compañía S.A., bastando para ello que le comuniquen el convenio. En tal sentido, el artículo 8 de la Ley General de Sociedades se presenta, en principio, como una excepción al principio de relatividad contractual previsto en el artículo 1363 del Código Civil.

Ello vuelve necesario que Tercera Compañía S.A. se plantee algunas preguntas, como ¿qué implica que el convenio le sea exigible?, ¿qué obligaciones, deberes y cargas le puede imponer el convenio?, ¿qué ocurre si el convenio es contrario a las leyes que le son aplicables?, ¿qué ocurre si solo algunos accionistas celebraron el convenio?, ¿qué ocurre si el convenio le afecta negativamente o a terceros?, ¿cuál es el alcance de las restricciones impuestas sobre sus acciones, de ser el caso?, entre otras.

Estas son algunas de las interrogantes que nos plantearemos a lo largo de las siguientes líneas.

\section{ANÁLISIS DEL ARTÍCULO 8 DE LA LEY GENERAL DE SOCIEDADES}

\section{1. ¿Qué implica que el convenio le sea exigible a la sociedad?}

El primer punto a dilucidar es qué se debe entender cuando la Ley señala que los convenios de accionistas son válidos ante la sociedad y le son exigibles.

En lo que respecta a la validez, creemos que, al decir que los convenios son válidos ante la sociedad, dicho término no ha sido adecuadamente utilizado en la norma. A diferencia de la ineficacia funcional o de la inoponibilidad, la validez o invalidez de un acto jurídico no es relativa a alguien, sino que depende de la presencia o no de sus elementos esenciales -agente capaz, objeto física y jurídicamente posible, fin lícito y observancia de la forma

4. ELÍAS LAROZA, Enrique. "Derecho Societario Peruano. La Ley General de Sociedades del Perú". Tomo I. Lima: Gaceta Jurídica, 2015, pp. 81-82. 
prescrita bajo sanción de nulidad. Por tanto, un acto jurídico - i.e. un convenio de accionistas - no será válido porque la Ley General de Sociedades lo diga, sino porque contiene los elementos esenciales para su validez. De ser válido, no lo será solo ante la sociedad, sino erga omnes. El artículo sería más preciso eliminando la mención a la validez y reemplazándolo por el concepto de oponibilidad frente a la sociedad.

El análisis respecto de la exigibilidad es bastante menos ocioso.

La exigibilidad de un acto jurídico es entendida como sinónimo de la obligatoriedad y se refiere a la posibilidad de requerir su cumplimiento, de ser necesario, de manera forzosa a través de la vía jurisdiccional que corresponda ${ }^{5}$.

Lo anterior significa que, conforme al artículo 8 de la Ley General de Sociedades, un convenio de accionistas comunicado a la sociedad le genera obligaciones a la misma, aun cuando esta no haya brindado su consentimiento. Por tanto, al recibir la comunicación acerca de un convenio de accionistas, la administración de la sociedad está obligada a disponer de los medios necesarios para poder hacerlo cumplir, sin haber tenido la oportunidad de hacer una evaluación de la conveniencia de sus efectos, de su compatibilidad con el objeto de la sociedad y sus objetivos estratégicos, de la disponibilidad de recursos financieros y humanos para la ejecución de las prestaciones que correspondan, etc.

En palabras de Daniel Abramovich, "(...) esto significa que, ante la correcta comunicación a la sociedad del convenio, esta debe adoptar una posición activa que garantice su cumplimiento"6.
Dado que el artículo 8 únicamente señala que los convenios de accionistas le son exigibles a la sociedad en todo cuanto le sea concerniente, no existe un límite al universo de obligaciones que dichos convenios le pueden imponer a la sociedad, salvo por lo establecido en el segundo párrafo del artículo 8 en cuestión al señalar que "[s]i hubiera contradicción entre alguna estipulación de dichos convenios yel pacto social o el estatuto, prevalecerán estos últimos, sin perjuicio de la relación que pudiera establecer el convenio entre quienes lo celebraron".

Sin embargo, los objetivos estratégicos de la sociedad y otros asuntos de interés social no se encuentran comprendidos en el pacto social o el estatuto. La salvedad solo es útil en caso que el convenio de accionistas contravenga directamente una disposición del pacto social o del estatuto, como por ejemplo si contraviniese el régimen para la transferencia de acciones regulado en el mismo u obligase a la sociedad a operar de modo incompatible con su objeto social.

Al respecto, Julio Salas se ha preguntado si:

"(...) entonces, ¿tiene que entenderse que, por el solo hecho de la debida comunicación, todo y cualquier convenio celebrado entre socios o entre estos y terceros es válido y exigible a la sociedad, cualquiera que sea la estipulación que contenga?"

Ante ello, señala que "es claro que no y que tienen que reconocerse límites a la autonomía de la voluntad de los celebrantes"'.

El mismo autor señala como ejemplos de dichos límites (i) las normas legales imperativas; (ii) las cláusulas que contravienen el pacto social o el estatuto; y (iii) las cláusulas que contravienen

5. "Naturaleza de lo que por derecho en uno u obligación en otro puede recabarse imperativamente | Circunstancia que acompaña a una potestad jurídica para su efectividad, incluso coactiva." CABANELLAS, Guillermo. "Diccionario Enciclopédico de Derecho Usual". Vigésima Edición. Tomo III. Buenos Aires: Editorial Heliasta, 1981.

6. ABRAMOVICH ACKERMAN, Daniel. "Una aproximación práctica a los convenios de accionistas en la sociedad anónima". lus et veritas №20. Lima: Editorial PUCP, 2000, p. 156.

7. SALAS SÁNCHEZ, Julio. "Los convenios de accionistas en la Ley General de Sociedades y la autonomía de la voluntad". lus et Veritas $\mathrm{N}^{\circ}$ 36. 2008. p. 76. 
los principios configuradores de la sociedad anónima - por ejemplo, no sería posible pactar que la sociedad no cuente con un capital social o pactar en contra de la responsabilidad limitada de los accionistas-.

Coincidimos con el citado autor en los límites señalados y en que el universo de obligaciones que los convenios de accionistas pueden imponerle a la sociedad no debe ser irrestricto.

Sin embargo, consideramos que no todo "lo que le sea concerniente" a la sociedad le debería poder ser exigido y que debieran ser aplicables algunos límites adicionales. Creemos que los convenios de accionistas a los que se refiere el artículo 8 de la Ley General de Sociedades deberían tener por objeto regular las relaciones entre ellos y la forma en la que ellos interactúan con la sociedad, todo lo cual debe ser oponible a la esta última. No obstante, salvo que la sociedad sea parte en el convenio, las obligaciones que son exigibles a la sociedad deberían limitarse a aquellas indispensables para brindar un marco en el cual se permita el cumplimiento del convenio y a la obligación de no hacer consistente en no reconocer actos de los accionistas realizados en incumplimiento del convenio, siempre que tales actos conciernan a la sociedad.

Lo anterior no quiere decir que, dentro de la autonomía privada y el derecho contractual, los accionistas no puedan establecer entre ellos todas las obligaciones que consideren convenientes, incluso en la forma de promesas de la obligación o del hecho de un tercero ${ }^{8}$, siendo este tercero la sociedad. Lo que proponemos es que el derecho societario debería precisar en qué casos estos acuerdos de diverso contenido pueden generar directamente obligaciones para la sociedad, sin que esta haya brindado su consentimiento.

Por ejemplo, si el convenio de accionistas establece un sindicato de votos, la sociedad no deberá reconocer un voto emitido en incumpli- miento del convenio. O si el convenio establece una limitación a la transferencia de las acciones de propiedad de las partes, la sociedad no deberá reconocer una transferencia realizada sin cumplir con lo previsto en dicho convenio. Así, el rol de la sociedad es de ser una suerte de supervisora del cumplimiento del convenio en todo lo que le es concerniente.

Siendo ello así, y no existiendo actualmente restricciones legales al contenido de los convenios de accionistas, ante la comunicación de un convenio a la sociedad, la administración debe hacer una evaluación de su contenido y determinar si puede asegurar su cumplimiento.

En caso de que la administración de la sociedad llegue a la conclusión de que no puede hacer cumplir el convenio y, por tanto, se oponga a cumplirlo, la consecuencia del texto actual del artículo 8 de la Ley General de Sociedades, que utiliza el concepto de exigibilidad, es que los accionistas que son parte del convenio podrían exigir su cumplimiento jurisdiccionalmente y demandar los daños y perjuicios que correspondan. Incluso, si cuentan con la mayoría necesaria en la junta general de accionistas, podrían iniciar una pretensión social de responsabilidad contra el directorio o gerente general por la negativa a su cumplimiento. Ello será de aplicación aun cuando el cumplimiento del convenio por parte de la sociedad pueda serle perjudicial a esta o a los demás accionistas que no participaron en el convenio.

Sumado a ello, existe la posibilidad de que la administración interprete erróneamente el contenido del convenio y no asegure su cumplimiento conforme a la común intención de las partes que lo celebraron, considerando que los administradores no necesariamente son abogados o tienen experiencia en la interpretación de contratos.

Creemos que, en estas ocasiones, se pueden generar consecuencias no deseadas para el

8. Conforme al artículo 1470 del Código Civil. 
correcto funcionamiento de la sociedad y para las relaciones entre los accionistas.

Estos riesgos ya han sido advertidos previamente. De acuerdo a Daniel Abramovich:

"(...) no estamos en desacuerdo con la inclusión de la exigibilidad de convenios de accionistas o entre estos y terceros frente a la sociedad; sin embargo, la falta de determinación de algunos aspectos sustanciales con respecto a las obligaciones que asume la sociedad con respecto a la ejecución de dichos convenios podría redundar en un perjuicio directo en contra de la sociedad $-y$ en consecuencias indirectas en contra de los accionistas de esta - y eventualmente también en contra de los accionistas o terceros que podrían verse perjudicados de la interpretación y/o ejecución incorrecta de estos"

Limitar el tipo de obligaciones que los convenios de accionistas pueden imponerle a la sociedad podría resolver los problemas identificados. En todo caso, a fin de evitar la sobre regulación y de no establecer un régimen demasiado restrictivo, la norma podría señalar que los convenios de accionistas le son siempre oponibles a la sociedad, pero le son exigibles solo en todo cuanto se refiera a las relaciones entre los accionistas que forman parte del convenio correspondiente, desde que le es comunicado, de modo que la sociedad tendrá una obligación de no hacer consistente en no reconocer actos de los accionistas realizados en incumplimiento del convenio correspondiente. En caso se quiera que la sociedad asuma obligaciones adicionales propias - con los recursos humanos y financieros que ello requiere - bajo el convenio, esta debe intervenir en dicho convenio y obligarse expresamente, de modo que la asunción de dichas obligaciones y su conveniencia haya podido ser evaluada por el Directorio y/o por la Junta General de Accionistas, respetando las reglas para la adopción de acuerdos y los poderes vigentes.

Por ejemplo, se podría establecer como limitante para la exigibilidad a la sociedad los deberes fiduciarios de los directores. De acuerdo al Comité de Derecho Societario de la Asociación de la Barra de Nueva York - Corporation Law Committee of the Association of the Bar of the City of New York-:

\begin{abstract}
"Aunque algunos convenios de accionistas pretenden exigir a cada accionista a causar que el director que haya nombrado vote de determinada manera respecto de ciertos asuntos, este enfoque no asegurará que los accionistas vean materializado el beneficio de este derecho negociado porque los directores tienen deberes fiduciarios de actuar en beneficio de los intereses de la sociedad y de todos sus accionistas, con prescindencia de los intereses de cualquier accionista individual. Estos deberes fiduciarios no pueden ser derogados por convenios privados"10(traducción libre).
\end{abstract}

Aunque se trate de una limitación sencilla en concepto, asigna la responsabilidad de proteger los intereses de la sociedad y de todos sus accionistas en el órgano responsable de la interpretación y aplicación del convenio por parte de la sociedad.

\section{Sobre las partes en el convenio de accionistas.}

Como ya adelantamos, un convenio puede ser celebrado por todos los accionistas de la sociedad, por solo algunos de ellos, por accionistas y terceros y, además, en cualquiera de los casos, con la participación de la sociedad o sin esta. Conforme a una interpretación literal del artículo 8 de la Ley General de Sociedades, basta que

9. ABRAMOVICH ACKERMAN, Daniel. Óp. Cit. p. 157.

10. Corporation Law Committee of the Association of the Bar of the City of New York. "The Enforceability and Effectiveness of Typical Shareholders Agreement Provisions". Disponible en: <http://www.nycbar.org/pdf/report/ uploads/20071830-TheEnforceabilityandEffectivenessofTypicalShareholderAgreementProvisionsforweb.pdf $>$. 
el convenio sea comunicado a la sociedad para que, en todos estos supuestos, le sea exigible.

Sin embargo, creemos que el principio de relatividad contractual es útil para hacer algunas diferenciaciones al proponer algunas mejoras al artículo 8 de la Ley General de Sociedades, sumado a las consideraciones expresadas en la sección 4.1 anterior.

El supuesto más sencillo es aquel en el que todos los accionistas y la sociedad participan en el convenio, en cuyo caso la exigibilidad plena para todas las partes es evidente.

En el caso de que la mayoría de los accionistas participen en el convenio, pero la sociedad no, creemos que, si bien los mismos accionistas reunidos en junta general podrían causar que la sociedad asuma las obligaciones bajo el convenio, no resulta admisible establecer que el convenio le es exigible a la sociedad, salvo en cuanto a la obligación de no hacer consistente en no reconocer actos de los accionistas realizados en contravención del convenio. Antes de que la sociedad asuma obligaciones adicionales bajo el convenio, la Junta General de Accionistas o el Directorio, según corresponda, deberá haber aprobado la participación de la sociedad en el mismo, brindando su consentimiento expreso.

Aun en el supuesto de que todos los accionistas sean parte en el convenio, consideramos que no basta ello para su exigibilidad plena frente a la sociedad, con que todos los accionistas firmen el convenio para que este le sea exigible a la sociedad, salvo en cuanto a la obligación de no hacer consistente en no reconocer actos de los accionistas realizados en contravención del convenio.

Ello se debe a que la voluntad social debe formarse en la junta general de accionistas o en el órgano al que le corresponda tal decisión conforme a su estatuto. En la junta, los accionistas que no hayan votado a favor del acuerdo gozan de ciertas protecciones que no tendrían de admitirse la exigibilidad automática con la sola comunicación del convenio a la sociedad. Específicamente, tienen el derecho de ser informados sobre el contenido del convenio antes de que la sociedad se obligue bajo el mismo. Adicionalmente, tienen el derecho a expresar su desacuerdo en la junta y a hacer constar en el acta su voto, así como a impugnar el acuerdo y, de ser el caso, impedir que la sociedad se obligue bajo el convenio.

Por su parte, los terceros legitimados pueden interponer acciones de nulidad contra el acuerdo, conforme a la Ley General de Sociedades, aun cuando haya sido adoptado en junta universal.

Adicionalmente, el Directorio, como órgano de administración, es el órgano que con mayor probabilidad cuenta con la información necesaria para evaluar la conveniencia del convenio para la sociedad y, en caso de tener tal atribución conforme al estatuto de la misma, podría ser el órgano idóneo para decidir la intervención de la sociedad en dicho convenio, encontrándose sujeto a los recursos impugnatorios y responsabilidades que prevé la Ley General de Sociedades.

En caso que solo algunos accionistas - ya sea que representen a la mayoría o no-y la sociedad sí sean parte en el convenio, el mismo sí debiera ser exigible a todas las partes, incluida la sociedad, bajo el entendido que ésta última lo ha suscrito por medio de sus representantes quienes han sido debidamente autorizados por la junta general de accionistas o el directorio, según corresponda. Las consecuencias son las mismas tratándose de convenios entre accionistas y terceros, según intervenga o no la sociedad.

Es nuestra opinión que la interpretación del artículo 8 de la Ley General de Sociedades de manera sistemática con el artículo 1363 del Código Civil debiera dar como resultado lo señalado en cada supuesto.

\section{La calidad de accionista como condición de eficacia de un convenio de accionistas.}

Como hemos señalado, existen convenios entre accionistas exclusivamente, así como existen convenios entre accionistas y terceros.

Un aspecto que la Ley General de Sociedades no prevé es qué ocurre si todos o alguno de los 
accionistas que son parte del convenio dejan de tener la condición de accionistas.

Somos de la opinión de que la pérdida de la calidad de accionista no genera automáticamente la pérdida de eficacia del convenio de accionistas, sino que dependerá de cuántas partes dejan de ser accionistas y del objeto de cada una de las prestaciones acordadas.

Aquellas disposiciones del convenio que requieran necesariamente la propiedad de acciones o se deriven de los derechos inherentes a la calidad de accionista, quedarán sin efecto respecto de la parte que deja de serlo por imposibilidad de la prestación -artículo 1431 del Código Civil-. Por ejemplo, todas aquellas disposiciones contenidas en el convenio referidas al ejercicio del derecho a voto en Junta General de Accionistas quedarán sin efecto, así como las disposiciones típicas de derechos de arrastre — drag-along - y acompañamiento -tag-along-.

Sin embargo, hay otras prestaciones que no perderían necesariamente su objeto cuando alguno de los accionistas deje de serlo. De este modo, el convenio se convertiría en un convenio entre accionistas y terceros. El caso más evidente es la obligación de confidencialidad que suele ser incluida en los convenios de accionistas. Otros ejemplos menos evidentes podrían incluir aquellas disposiciones referidas a la transferencia de acciones. Por ejemplo, si el convenio incluía un derecho de adquisición preferente para las partes, ¿el tercero que ya no es accionista aún mantendría un derecho de adquirir preferentemente las acciones de las demás partes en caso de transferencia? Si el convenio establecía ciertos derechos de veto no atados a la Junta General de Accionistas, ¿el tercero podría continuar ejerciéndolos pese a no ser accionista?

Por otro lado, en el caso de que todas las partes dejen de ser accionistas, es razonable que el convenio pierda su objeto, al no existir la causa que subyace a su celebración -la propiedad común de acciones en la sociedad-. Sin embargo, si existiesen obligaciones que mantienen su objeto - por ejemplo, confidencialidad u otras obligaciones accesorias-, el convenio no que- dará resuelto sino que se mantendrá vigente únicamente respecto de lo que mantenga su objeto.

Creemos que las respuestas dependerán del resultado de la interpretación de las cláusulas aplicables en cada convenio. Sin embargo, mantenemos que dado que el convenio no queda resuelto automáticamente por haber perdido las partes la calidad de accionista ni deja de encontrarse vinculada bajo el convenio la parte que dejó de ser accionista por dicha razón, debe regularse de manera expresa en el convenio las consecuencias deseadas en cada caso.

\section{EFECTOS DE LA ANOTACIÓN DEL CONVENIO EN LA MATRÍCULA DE ACCIONES Y DE LA INSCRIPCIÓN REGISTRAL}

Conforme al artículo 92 de la Ley General de Sociedades, pueden anotarse en la matrícula de acciones "(...) los convenios entre accionistas o de accionistas con terceros que versen sobre las acciones o que tengan por objeto el ejercicio de los derechos inherentes a ellas".

Por su parte, de acuerdo al artículo 3, inciso (i) del Reglamento de Registro de Sociedades, son actos inscribibles "(...) los convenios societarios entre socios que los obliguen entre sí y para con la sociedad, siempre que no versen sobre las acciones y no tengan por objeto el ejercicio de los derechos inherentes a ellas".

Es claro, entonces, que los convenios que versen sobre las acciones se registran en el registro privado llamado matrícula de acciones y no gozan de las protecciones que otorga la publicidad registral. Contrariamente, los convenios que no versen sobre las acciones ni sobre los derechos inherentes a ellas, sí pueden gozar de publicidad registral, siendo aplicables a ellos los principios regulados en los artículos 2012 y siguientes del Código Civil.

Siendo ello así, cabe hacer algunos comentarios sobre el efecto de la anotación en la matrícula de acciones.

Dado que el artículo 8 de la Ley General de Sociedades prevé que los convenios son exigibles 
a la sociedad desde que le son comunicados, el primer punto es que no es necesaria la anotación en la matrícula para la oponibilidad frente a la sociedad. Una vez anotados, serán oponibles frente a los accionistas quienes podrán tomar conocimiento de los mismos.

Sin embargo, los actos anotados en la matrícula de acciones no son oponibles a terceros. Siendo un libro privado que le pertenece a la sociedad, si bien la Ley General de Sociedades no lo establece expresamente, este solo debiera ser libremente accesible por sus accionistas que representen el $5 \%$ o más del capital pagado de la sociedad conforme al artículo 52-A de la Ley General de Sociedades, sin perjuicio de que el gerente general podría disponer voluntariamente brindar información acerca del contenido de dicho libro.

En caso de que la sociedad no acceda a brindar información sobre el contenido de la matrícula, ello podría generar una gran asimetría de información entre un accionista que desee vender sus acciones y un tercero adquirente, quien deberá verificar la titularidad sobre las acciones y las cargas que puedan pesar sobre ellas únicamente a través de la información que el vendedor le provea.

En ese supuesto, adquieren gran relevancia las obligaciones de saneamiento del vendedor, conforme a los artículos 1484 y siguientes del Código Civil, con los remedios aplicables a cada caso según dichas normas, en vista a que el adquirente no tendrá, por sus propios medios, acceso a la información sobre la titularidad y las cargas que podrían pesar sobre la acción y no se encontrará protegido por el principio de buena fe registral.

Tratándose, por ejemplo, de cargas impuestas por un convenio de accionistas, se deberá evaluar si dichas cargas califican como vicios ocultos que impiden darle al bien adquirido "(...) el destino normal de acuerdo con sus características, la oportunidad de la adquisición y las costumbres del lugar (...)", conforme al artículo 1486 del Código Civil.

Asimismo, en caso de que el convenio anotado en la matrícula contenga restricciones a la transferencia, la sociedad no podrá reconocer una transferencia efectuada en contravención del convenio. Sin embargo, no existiría una causal de nulidad ni de ineficacia del convenio - salvo frente a la sociedad y a las partes en el convenio- aun cuando, como es usual, el convenio establezca dicha consecuencia. Por tanto, el tercero habrá adquirido las acciones en un acto jurídico válido, pero no podrá ejercer los derechos inherentes a la calidad de accionista. Creemos que tal limitación daría también origen a los remedios previstos para el incumplimiento de obligaciones de saneamiento, por tratarse de un vicio oculto que restringe el ejercicio pleno del derecho de propiedad.

De este modo, las restricciones impuestas sobre las acciones y otras cargas que pueden establecerse mediante convenios de accionistas, no persiguen a la acción sobre la cual recaen como si se tratasen una suerte de derechos reales, sino que únicamente generan efectos obligacionales entre las partes e impidiendo a la sociedad reconocer actos en contravención de dichos convenios.

Creemos que en estos casos se trataría de"(...) cargas, limitaciones o gravámenes ocultos y de los que no se dio noticias al celebrarse el contrato, si estos son de tanta importancia que disminuyen el valor del bien, lo hacen inútil para la finalidad de su adquisición o reducen sus cualidades para ese efecto" - artículo 1509 del Código Civil-y que, por tanto, calificarían como vicios ocultos.

Tratándose de convenios inscritos en el Registro de Sociedades, estos sí son oponibles frente a terceros adquirentes, pero dado que estos no pueden versar sobre las acciones, la inscripción registral únicamente genera el efecto de que dichos terceros tomen conocimiento del convenio, mas no que se vean obligados bajo sus disposiciones por la sola adquisición de acciones de la sociedad.

Se deberá evaluar en cada caso si corresponde o resulta conveniente la anotación en la matrícula y/o la inscripción registral del convenio de accionistas, según los efectos buscados. 


\section{CONCLUSIONES}

Por las razones expuestas en las secciones precedentes, creemos que sí hay un gran espacio de mejora en nuestra Ley General de Sociedades para poder incluir algunas disposiciones que regulen el alcance de los convenios de accionistas y los supuestos en los que son exigibles frente a la sociedad. Estas disposiciones se verían alimentadas por la evolución de la práctica societaria y comercial, la cual ha sido significativa desde la entrada en vigencia de nuestra actual Ley General de Sociedades en 1998.

El desarrollo de los negocios e inversiones en los últimos años ha ido lentamente cambiando la estructura típica de las sociedades en el Perú, que solían ser de muy pocos accionistas, con cierta afinidad entre sí y cuyos intereses estaban alineados con los de la sociedad.

Hoy en día, el ingreso de otros perfiles de inversionistas a las sociedades, tales como fondos de inversión y Administradoras de Fondos de Pensiones - "AFPs" - , y la lenta aparición de más sociedades con accionariado difundido exigen que la sociedad tenga mucha claridad sobre lo que los convenios de accionistas pueden exigirles y que la administración de la sociedad pueda cumplir con sus deberes fiduciarios frente a la sociedad misma y a todos sus accionistas.

Mientras que no se realicen las modificaciones necesarias, se requerirá continuar interpretando el artículo 8 de la Ley General de Sociedades no de manera literal, sino de manera restringida conforme al principio de relatividad contractual. 